OPEN ACCESS

Edited by:

David Quentin Beversdorf University of Missouri, United States

Reviewed by:

Chiara Verpelli,

Institute of Neuroscience (CNR), Italy

Rong Zhang,

Peking University, China

${ }^{*}$ Correspondence:

Li Chen

chenli@cqmu.edu.cn:

chenli2012@126.com

Specialty section: This article was submitted to

Autism,

a section of the journal

Frontiers in Psychiatry

Received: 05 November 2021

Accepted: 10 February 2022

Published: 08 March 2022

Citation:

Li X, Zhou P, Li Q, Peng B, Cun Y, Dai $Y$, Wei H, Liu X, Yu Y, Jiang $Z$, Fan $Q$, Zhang $Y$, Yang T, Chen J, Cheng Q, Li T and Chen L (2022) Regressive Autism Spectrum

Disorder: High Levels of Total Secreted Amyloid Precursor Protein and Secreted Amyloid Precursor Protein- $\alpha$ in Plasma.

Front. Psychiatry 13:809543 doi: 10.3389/fpsyt.2022.809543

\section{Regressive Autism Spectrum Disorder: High Levels of Total Secreted Amyloid Precursor Protein and Secreted Amyloid Precursor Protein- $\alpha$ in Plasma}

\author{
Xiaoli Li ${ }^{1,2,3,4,5}$, Ping Zhou 1,2,3,4,5, Qiu Li ${ }^{2,3,4,5}$, Bin Peng ${ }^{6}$, Yupeng Cun ${ }^{3,4,5}$, Ying Dai ${ }^{1,2,3,4,5}$, \\ Hua Wei ${ }^{1,2,3,4,5}$, Xiao Liu 1,2,3,4,5, Yang Yu ${ }^{1,2}$, Zhiyang Jiang ${ }^{1,2,3,4,5}$, Qiongli Fan ${ }^{7}$, \\ Yuping Zhang ${ }^{7}$, Ting Yang ${ }^{1,2,3,4,5}$, Jie Chen ${ }^{1,2,3,4,5}$, Qian Cheng ${ }^{1,2,3,4,5}$, Tingyu $L^{1,2,3,4,5}$ and \\ Li Chen ${ }^{1,2,3,4,5 *}$
}

${ }^{1}$ Growth, Development, and Mental Health of Children and Adolescence Center, Children's Hospital of Chongqing Medical University, Chongqing, China, ${ }^{2}$ Chongqing Key Laboratory of Child Health and Nutrition, Chongqing, China, ${ }^{3}$ Ministry of Education Key Laboratory of Child Development and Disorders, Chongqing, China, ${ }^{4}$ China International Science and Technology Cooperation Base of Child Development and Critical Disorders, Chongqing, China, ${ }^{5}$ National Clinical Research Center for Child Health and Disorders, Chongqing, China, ${ }^{6}$ School of Public Health and Management, Department of Health Statistics, Chongqing Medical University, Chongqing, China, ' Department of Pediatrics, Xinqiao Hospital, Army Medical University, Chongqing, China

Autism spectrum disorder (ASD) is a complex neurodevelopmental disorder characterized by social communication difficulties, repetitive behaviors, and parochial interests. Individuals with regressive ASD (RA), a unique subtype, have poor outcomes. Moreover, there are currently no validated blood-based biomarkers for ASD, hindering early diagnosis and treatment. This study was the first to examine plasma levels of total secreted amyloid precursor protein (sAPPtotal), secreted amyloid precursor protein- $\alpha$ (SAPP $\alpha$ ), and secreted amyloid precursor protein- $\beta$ (SAPP $\beta$ ) in children diagnosed with RA $(n=23)$ and compare them with the levels in age-matched children with non-regressive ASD (NRA) $(n=23)$ and typically developing (TD) controls $(n=23)$. We found that SAPPtotal and SAPP $\alpha$ levels were significantly higher in children with RA than in children with NRA or in TD controls. In contrast, no difference was observed in SAPP $\beta$ levels. In conclusion, increased plasma levels of SAPPtotal and SAPP $\alpha$ may be valuable biomarkers for the early identification of ASD regression. Prospective studies will be conducted using a larger sample to further investigate these differences.

Keywords: autism spectrum disorder, regression, amyloid precursor protein, sAPP $\alpha$, biomarkers

\section{INTRODUCTION}

Autism spectrum disorder (ASD) is a neurodevelopmental disorder that emerges in early childhood and is characterized by social communication difficulties, repetitive behaviors, and parochial interests (1). Since the first description by psychiatrist Dr. Sukhareva, ASD has evolved from a rare to a widespread disease, with a prevalence of $\sim 1.85 \%$, and has become a major public health problem affecting social and economic development $(2,3)$. Overall, ASD has a serious impact on individuals, families, and societies. 
The etiology and phenotypes of ASD are heterogeneous and determined by a complex combination of genetics and the environment $(4,5)$. At present, the diagnosis of ASD depends on behavioral descriptions and characteristic observations (6), with the average age at diagnosis being 5 years old (7). According to one prospective study, children with ASD exhibit social abnormalities and stereotyped behaviors at 6 months, but these subtle changes are usually ignored by parents (8). Early screening and diagnosis of ASD are very challenging, and the American Academy of Pediatrics recommends that children be screened early and continuously tested before the age of 2 years (9). Although behavioral interventions can improve outcomes, there are no drugs that completely alleviate the symptoms of ASD $(10,11)$. Importantly, earlier and more frequent behavioral interventions for autism lead to better outcomes (11). Notably, individuals with regressive ASD (RA), a complex subtype of the ASD phenotype, consistently have poor outcomes $(12,13)$, which may be related to the fact that individuals with RA show poorer language development, more severe autism, and lower intellectual function than those with non-regressive ASD (NRA) (14) as well as to the neurological and pathological bases of regression. At present, RA is a hot research topic.

Although the complex phenotypic causes and pathogenesis of RA have been explored for more than a century, no conclusions have yet been drawn (15). Tan et al. reported that the incidence of RA is up to $30 \%$ and that it generally occurs at the age of 19.8 months. Among individuals with RA, 20\% exhibit language regression, $40 \%$ present language/social regression, 30\% show mixed regression, and $27 \%$ exhibit unspecified regression (16). A recent prospective report pointed out that information reported by parents is only the tip of the iceberg and that the actual incidence of RA is as high as $80 \%$ (8). It has also been reported that immune disorders or neuroinflammation may be involved in the etiology of regression $(17,18)$. The only evidence involves data from metabonomics and immunology studies of older children $(19,20)$, and there are few biomarkers in early childhood in RA. Therefore, major goals are identifying early specific biomarkers and diagnostic tools for ASD and its subtypes before core symptoms and regression emerge.

Previous studies have identified 206 autism-susceptibility genes that converge on the amyloid precursor protein (APP) metabolic pathway (21). APP protein is a glycoprotein secreted by glial cells and neurons that promotes neuronal proliferation and migration, cell adhesion, and synapse formation $(22,23)$. In the non-amyloidogenic pathway, APP is cleaved by $\alpha$ - and $\gamma$ secretase liberates secreted APP- $\alpha(\mathrm{sAPP} \alpha)$ and $\mathrm{p} 3$ peptide (24). However, if APP is initiated by $\beta$ - and $\gamma$-secretase, then secreted $\mathrm{APP}-\beta(\mathrm{AAPP} \beta)$ and neurotoxic $\mathrm{A} \beta$ peptides are generated, which are often involved in Alzheimer's disease (AD) and

\footnotetext{
Abbreviations: ASD, autism spectrum disorder; RA, regressive autism; NRA, nonregressive autism; APP, amyloid precursor protein; sAPP $\alpha$, secreted APP- $\alpha$; sAPP $\beta$, secreted APP- $\beta$; sAPP $\gamma$, secreted APP- $\gamma$; sAPPtotal, total secreted APP; $\mathrm{A} \beta$, amyloid- $\beta$; AD, Alzheimer's disease; ChiCTR, Chinese Clinical Trial Registry; DSM-5, Diagnostic and Statistical Manual of Mental Disorders, 5th edition; CARS, Childhood Autism Rating Scale; CDD, childhood disintegrative disorder; TD, typically developing; LTD, long-term depression; iNOS, inducible nitric oxide synthase; BBB, blood-brain barrier.
}

neurodegeneration (25-27). Notably, if APP is cleaved by $\gamma$ secretase at the C-terminus of the A $\beta$ domain, secreted APP$\gamma(\mathrm{sAPP} \gamma)$ may be released, and $\operatorname{sAPP} \alpha, \operatorname{sAPP} \beta$, and $\operatorname{sAPP} \gamma$ comprise total secreted APP (sAPPtotal) in human plasma (28). Plasma levels of sAPPtotal in individuals with severe and aggressive autism, a subtype of autism, are reportedly two or more times higher than those in children without autism (29). Moreover, sAPP $\alpha$-overexpressing mice exhibit autism-like behavior and reduced social and exploratory behavior (30). Nevertheless, it remains unclear whether APP and its metabolites are involved in the pathophysiological pathways underlying other autism phenotypes.

RA is a form of neurodegeneration that emerges only in childhood (31), and clarifying the specific pathophysiological pathway associated with regression, which may help identify early biomarkers for autism and other neurodegenerative diseases (such as $\mathrm{AD}$ ), would be a major advance in the field of neurodevelopment and neurodegeneration. Here, we investigated differences in the levels of sAPP isoforms in the plasma of children with and without RA. The identification of early specific biomarkers and associated pathophysiological pathways may guide the identification, diagnosis, and intervention before the emergence of the core symptoms and regression of ASD.

\section{MATERIALS AND METHODS}

\section{Ethics Statement}

The study protocol was approved by the Ethics Committee of the Children's Hospital of Chongqing Medical University (2019; Institutional Review Board Study Approval No. 292) and registered in the Chinese Clinical Trial Registry (ChiCTR) (registration number ChiCTR2000031194). The parents of all subjects provided written informed consent and their agreement for participation in our study. This study conformed to the Declaration of Helsinki.

\section{Participants and Blood Collection}

In total, 69 children aged 1.75-5.08 years who were treated at the Pediatrics Department of Children's Hospital of Chongqing Medical University were examined in this case-control study. Children with ASD $(n=46)$ had a confirmed diagnosis of autism according to the clinical criteria in the Diagnostic and Statistical Manual of Mental Disorders, 5th edition (DSM-5), as diagnosed by a proficient clinical psychologist, developmental pediatrician, or child psychiatrist. Using the Childhood Autism Rating Scale (CARS), we further determined symptoms of ASD, and those with CARS scores $\geq 30$ were included in the autism group (32). The judgment of ASD's regressive behavior in this study refers to the definition of the same type of research articles $(14,15,33,34)$, and interviews with the parents or caregivers on the child's development process. Notably, some children diagnosed with ASD initially show a period of apparently typical development followed by a considerable loss of previously established skills, a phenomenon termed "regression". Regression is defined as the loss of one or more developmental skills in the areas of personalsocial abilities, gross motor performance, and/or fine motor 
performance after those skills have been acquired and maintained for 3 months. For example, parents of an 18-month-old boy might be asked if the child used his index finger to indicate his needs. If the parents said the child used to but had stopped doing so, then they were asked when the ability had appeared and whether it had lasted more than 3 months before disappearing. If the parents answered yes, the child would be identified as having undergone regression in personal-social skills. Another type of regression is language regression, defined as the loss of more than five spoken words used communicatively in children over 18 months of age.

Exclusion criteria included participants comorbid with other developmental disorders or psychiatric diseases (e.g., Rett syndrome, cerebral palsy, chronic seizures, and other congenital diseases). Children with autism who had experienced regression and lost acquired skills or knowledge for at least 3 months were included in the RA group ( $n=23,3.16 \pm 0.77$ years old); age- and sex-matched children who did not experience regression were included in the NRA group ( $n=23,3.15 \pm 0.74$ years old). Among those who experienced regression, 12 exhibited language regression, four social regression, four mixed regression, and three another type of regression. Age- and sex-matched typically developing (TD) volunteers composed the control group ( $n$ $=23,3.16 \pm 0.88$ years old) (Table 1). Blood samples were collected, separated, and stored in strict accordance with the requirements of the experiment. The collection tubes containing EDTA and blood were centrifuged at $4^{\circ} \mathrm{C}$ at $1,000 \times \mathrm{g}$ for $10 \mathrm{~min}$, after which the top layer of plasma was carefully removed and transferred to an enzyme-free $1.5 \mathrm{ml}$ Eppendorf tube. The plasma was centrifuged at $4^{\circ} \mathrm{C}$ for $12 \mathrm{~min}$ and divided into equal portions to store at $-80^{\circ} \mathrm{C}$ for further analysis. It should be noted that the plasma aliquots underwent no more than 1 freeze cycle.

\section{Follow-Up}

After all the non-regressive children underwent protein measurements, their developmental progress was investigated by telephone follow-up every 3 months until they reached the age of 36 months. Children who underwent regression during follow-up were defined as having regressive ASD. The follow-up telephone calls asked the following questions:

(1) Did the child have gross motor, fine motor, or personal-social skills that suddenly disappeared or failed to progress after being mastered and maintained for more than 3 months, as opposed to being lost within a short period after the abilities appeared? Examples of personal-social skills were the ability to put on clothes and shoes with the help of their parents and button their clothes. Examples of gross motor skills were the ability to ride tricycles, jump on one foot, stand on one foot 2 out of 3 times for $5 \mathrm{~s}$, etc. Examples of fine motor skills were the ability to build eight-story towers, correctly choose the longer of two line segments three out of three times, copy a drawing of a cross, etc.

(2) Did the child lose more than five spoken words that had once been used communicatively? Examples include the ability to
TABLE 1 | Subject demographics.

\begin{tabular}{lcccc}
\hline & \multicolumn{2}{c}{ Autism spectrum disorder subtype } & $\begin{array}{c}\text { Typically } \\
\text { developing } \\
(\boldsymbol{n}=\mathbf{2 3})\end{array}$ \\
\cline { 2 - 4 } & $\begin{array}{c}\text { Total } \\
(\boldsymbol{n}=\mathbf{4 6 )}\end{array}$ & $\begin{array}{c}\text { Regression } \\
(\boldsymbol{n}=\mathbf{2 3})\end{array}$ & $\begin{array}{c}\text { No } \\
\text { regression } \\
(\boldsymbol{n}=\mathbf{2 3})\end{array}$ & \\
\hline $\begin{array}{l}\text { Age (y) } \\
\text { (mean } \pm \text { SD) }\end{array}$ & $3.17 \pm 0.75$ & $3.16 \pm 0.77$ & $3.15 \pm 0.74$ & $3.16 \pm 0.88$ \\
$\begin{array}{l}\text { Sex, } \\
n(\%) \\
\text { Male }\end{array}$ & $38(82.60)$ & $19(82.60)$ & $19(82.60)$ & $19(82.60)$ \\
\hline
\end{tabular}

say one's name, understand three to four prepositions, and speak a pair of antonyms.

On the other hand, it is generally believed that regression that occurs after 3 years of age should be defined as childhood disintegrative disorder (CDD) (35, 36). To reduce confounding factors, we generally do not include children with ASD who experience regression after age 3 .

\section{Analysis of Plasma sAPPtotal, sAPP $\alpha$, and SAPP $\beta$ Levels}

Concentrations of sAPPtotal, $\operatorname{sAPP} \alpha$, and $\operatorname{sAPP} \beta$ were detected by ELISA, as described by Erickson et al. (37-39). Plasma sAPPtotal concentrations were measured in duplicate using a commercial ELISA kit (IBL, Gunma, Japan). A $50 \mu$ l volume of plasma was diluted with $300 \mu \mathrm{l}$ enzyme immunoassay buffer and mixed evenly. A $100 \mu \mathrm{l}$ volume of the mixture was added to wells precoated with capture monoclonal anti-human APP (R12A1) and incubated overnight at $4^{\circ} \mathrm{C}$ after covering it with a plate lid. After washing several times, HRP-conjugated monoclonal anti-human APP (R101A4) was added to all wells and incubated the precoated plate for $30 \mathrm{~min}$ at $4^{\circ} \mathrm{C}$ after covering it with a plate lid. After several washes and the addition of the chromogen substrate, the colorimetric signal was detected at $450 \mathrm{~nm}$ using a microplate reader (Thermo). A standard curve was prepared by using known amounts of recombinant human APP protein, and the concentration for unknown samples was read from the standard curve. Levels of the other secreted APP isoforms were similarly measured using ELISA kits (IBL, Gunma, Japan).

\section{Statistical Analysis}

All data were analyzed by SPSS 25 and R language statistical analysis software, and the Shapiro-Wilk test was used to test the normality of all data sets. A descriptive analysis is presented as the means (standard deviation) or medians (interquartile ranges). The Friedman test was used to compare levels between groups; the Bonferroni post-hoc test was employed for post-hoc analyses between groups. Adjusted $p$-values $<0.05$ were considered statistically significant. Receiver operating characteristic (ROC) curve analysis was performed to define the discriminatory value of the sAPPtotal and sAPP $\alpha$ proteins to separate RA from NRA 
and TD. To verify the independent samples, we present the data in boxplots.

\section{RESULTS}

In our study, the sAPPtotal and sAPP $\alpha$ levels were significantly higher in the RA group than in the NRA and TD groups. Levels of sAPPtotal (Figure 1A) and sAPP $\alpha$ (Figure 1B) were different among diagnoses: TD $<\mathrm{NRA}<\mathrm{RA}$. In contrast, no differences in sAPP $\beta$ levels were observed in any two of the three groups. Individual results are presented in Figure 1. sAPPtotal levels were significantly higher in the RA group than in the NRA group ( $p=$ $0.001)$ or the TD group $(p=0.002)$. Interestingly, no significant differences were observed between the NRA and TD groups. Furthermore, RA showed higher sAPP $\alpha$ levels than NRA ( $p=$ 0.024 ), with no significant differences between NRA and TD. More remarkably, there were no differences in the sAPP $\beta$ levels of any two of the three groups $(p>0.05)$.

To better characterize the balance between the amyloidogenic and non-amyloidogenic pathways in autism, sAPP $\alpha /$ sAPPtotal and $\mathrm{sAPP} \beta / \mathrm{sAPPtotal}$ ratios were measured for each group. However, no significant differences were observed between any two of the three groups $(p>0.05)$ (Figure 2).

The use of sAPPtotal and sAPP $\alpha$ proteins as early specific biomarkers has predictive power to identify membership in the RA, NRA, and TD groups. Individual results are presented in Figure 3. The area under the ROC curve (AUC) of sAPPtotal for distinguishing RA from TD was 0.779, and the predictive AUC of independent sample validation was 0.75 . ROC curve analysis revealed an AUC of 0.687 for the sAPP $\alpha$ protein to separate RA from TD, and the predictive AUC of independent sample validation was 0.71 . In the RA and NRA groups, the AUC measurement for the sAPPtotal protein was 0.677 to separate RA from NRA, and the predictive AUC of independent sample validation was 0.7. ROC curve analysis revealed an AUC of 0.698 for the sAPP $\alpha$ protein to separate RA from NRA, and the predictive AUC of independent sample validation was 0.67.

\section{DISCUSSION}

Heller first defined regression as "dementia infantilis" in the early 20 th century, and after more than a century, its mechanism is still unknown $(15,40)$. One epidemiological investigation found that the risk of $\mathrm{AD}$ in autistic patients is 5 times higher than that in individuals without developmental disabilities (41). Notably, the accumulation of $A \beta$ in neurons is enhanced in the brains of idiopathic and dup15q11.2-q13 autism patients (42). APP metabolic pathways may be similar or different in individuals with RA and those with $\mathrm{AD}$, but the relationship is not clear.

In contrast to $\mathrm{AD}$, autism with regression of language, social or other abilities usually occurs in early childhood and gradually improves with age. Given the existence of neurodegenerative symptoms in early childhood in those with RA, we first examined differences between the levels of APP and its metabolites in children with and without RA. The results showed that plasma levels of sAPPtotal and sAPP $\alpha$ were higher in the RA group than in the NRA and TD groups, but there were no significant differences in SAPP $\beta$ levels between any two of the three groups.

High levels of sAPP $\alpha$ have been proven to be beneficial in the young adult brain, aged brain, and neurodegenerating brain (43). Indeed, studies on cultured neurons and animals have revealed that in the young brain, a high level of $\operatorname{sAPP} \alpha$ aids in neurite outgrowth (44), increases synaptic density (45), stimulates neural stem cell proliferation (46) and differentiation (47), and enhances spatial memory and memory consolidation (48). Furthermore, during aging and neurodegeneration, a high level of sAPP $\alpha$ reduces oxidative stress and cell death (49), rescues synaptic plasticity and synapse number (50) and spatial memory (51), and reduces $A \beta$ plaque deposition (52).

Nevertheless, excessive levels of sAPP $\alpha$ are harmful during the critical time window of brain development. During synaptic formation, excessive sAPP $\alpha$ reduces developmental spine pruning and impairs synaptic long-term depression (LTD), and changes in synaptic development and synaptic plasticity may result in ASD and memory impairment (53-55). In addition, excess sAPP $\alpha$ promotes the expression of inducible nitric oxide synthase (iNOS) in microglia, releasing glutamate and D-serine to cause neurotoxicity $(56,57)$. Moreover, an increased level of $\operatorname{sAPP} \alpha$ during the critical window of development induces overdifferentiation of neural stem cells into astrocytes and enhances the brain immune response by disrupting the IL6/gp130 pathway, leading to aberrant synaptic connections and brain damage (30).

However, it is worth noting where plasma sAPP, sAPP $\alpha$, and sAPP $\beta$ come from. Based on the present study, we cannot determine whether they come from the brain or the gut. To date, no studies have confirmed whether the $\operatorname{sAPP} \alpha$ protein originates from the gut or the brain. On the one hand, we consider that the SAPP $\alpha$ protein may come from the gut. In the last few years, the importance of gut microbiota impairment in the etiopathogenesis of pathologies such as autism and dementia has been raised (58). There has been an emerging interest in the possible role of the gut microbiota as a cofactor in the development of ASD; for example, serotonin is one of the possible links in the gut-brain-microbiome axis in $\operatorname{ASD}(59,60)$. Some studies found that microbiome differences in ASD patients may be related to dietary preferences related to stereotyped behavior or narrow interest, thus weakening the association between ASD and intestinal microbiota (61). However, accumulating evidence has shown a link between alterations in the composition of the gut microbiota and both gastrointestinal and neurobehavioral symptoms in children with ASD (62). Furthermore, studies have shown that gut microbial dysbiosis may lead to the secretion of amyloid, which disturbs gastrointestinal permeability and the blood-brain barrier (BBB). In this way, it may induce neuronal injury and ultimately lead to neuronal death (63-65). However, there is not enough evidence to prove whether the sAPP $\alpha$ protein, as an amyloid precursor protein cleavage product, can cross the $\mathrm{BBB}$ and have harmful effects during critical periods of brain development, which will be a very interesting and valuable research direction. On the other hand, we consider that sAPP $\alpha$ proteins may leak from the BBB. Studies have shown that excess sAPP $\alpha$ can activate microglia and astrocytes $(30,57)$, 

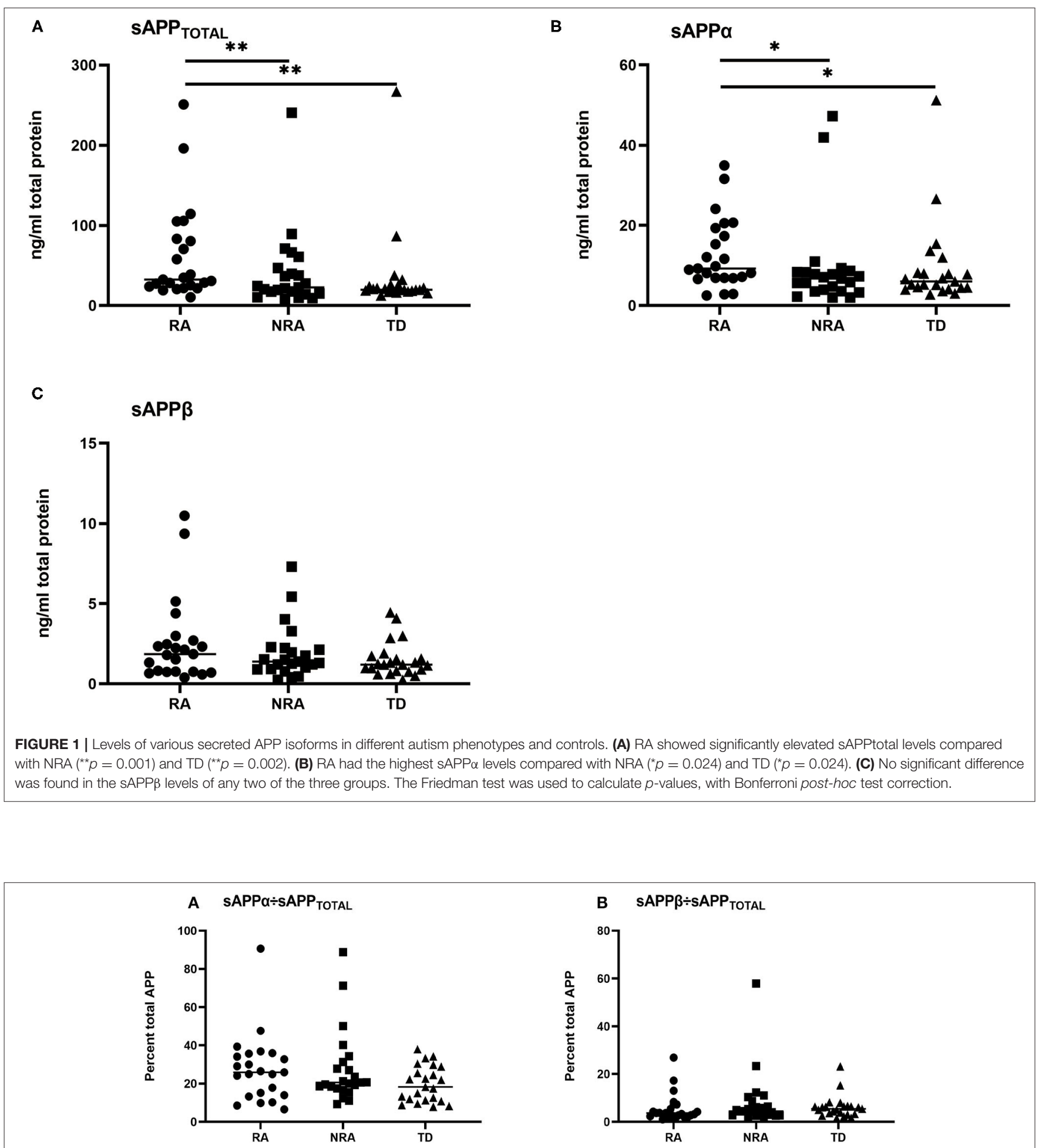

FIGURE 2 | Ratios of the levels of different secreted APP isoforms in children with ASD and controls. To further explore differences in sAPP $\alpha$, sAPP $\beta$, and sAPPtotal levels, the (A) SAPP $\alpha / \mathrm{sAPP}$ total ratio and (B) SAPP $\beta / \mathrm{SAPP}$ total ratio were measured for each group, and there was no difference in any pairwise comparison of the three groups $(p>0.05)$. The Friedman test was used to calculate $p$-values, with Bonferroni post-hoc test correction. 


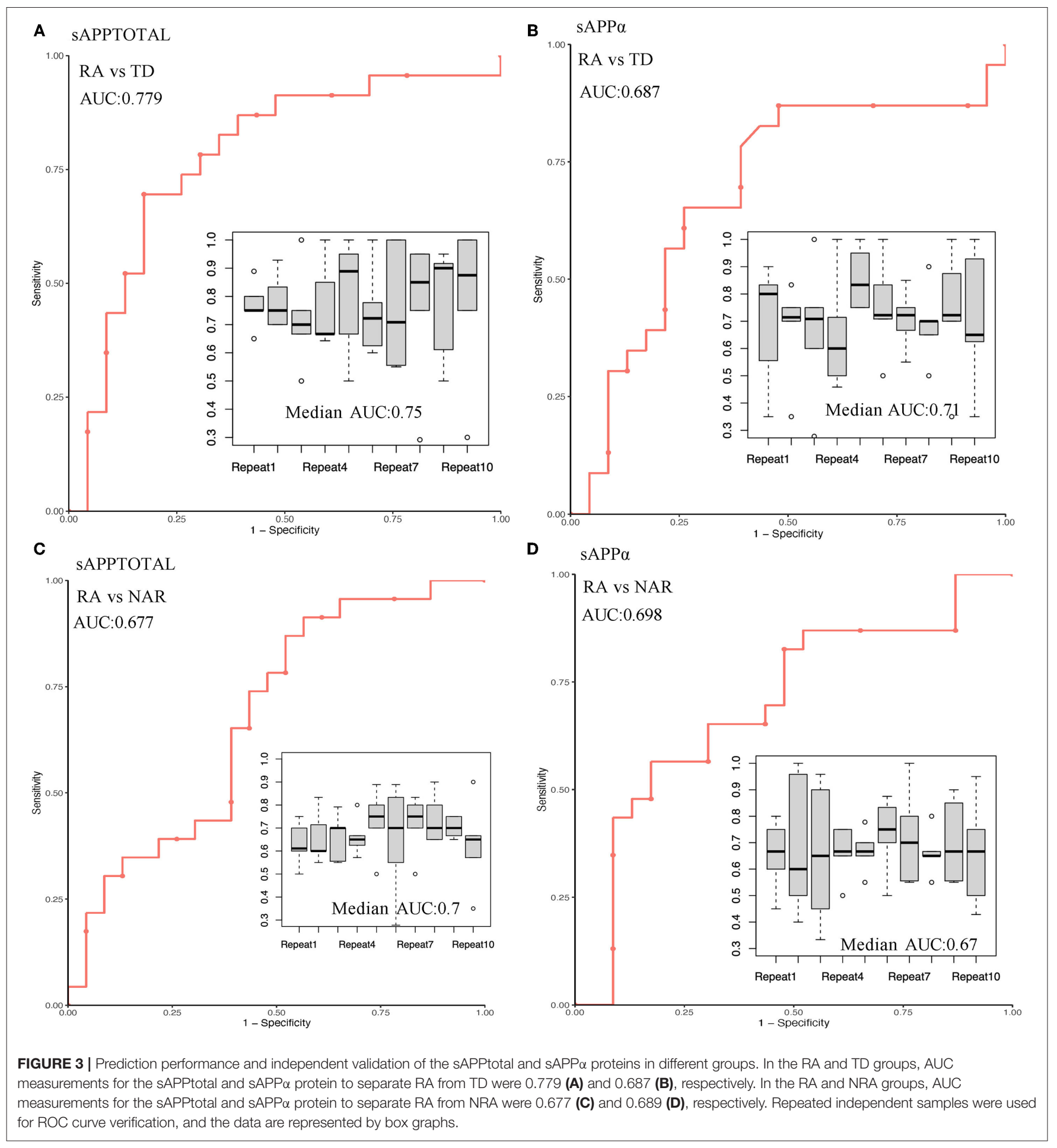

which contribute to BBB dysfunction (66), but it is unclear whether the SAPP $\alpha$ protein will leak from the damaged BBB, which needs to be further verified in animal experiments and will be a very valuable direction for our subsequent research. In conclusion, with the limitations of the current sample, we were able to obtain only peripheral blood in the hope of finding early predictive markers; in our next step, we will verify these markers in animal experiments to explore the source of all sAPP proteins. Significantly, in our study, compared with the RA and TD groups, children with regressive autism had higher sAPPtotal and SAPP $\alpha$ levels. It may be valuable for the early identification of ASD regression. 
RA, a distinct subtype of autism in which the nonamyloidogenic pathway may be preferentially active, may be the result of associated pathophysiological changes. In conclusion, we believe that an increase in sAPP $\alpha$ levels may reflect an early increase in the body's responsiveness but that an excessive increase in childhood may lead to neurotoxicity, aberrant synaptic connections, and brain damage. Therefore, inhibiting an abnormal increase in $\mathrm{SAPP} \alpha$ may help prevent the regression process. Overall, sAPPtotal and $\mathrm{sAPP} \alpha$ levels may serve as biomarkers for the early diagnosis and prognosis of RA.

Ray found that compared to other individuals (67), sAPP $\beta$ levels are decreased in individuals with severe autism; however, our study did not detect decreased levels of sAPP $\beta$ in children with RA. Notably, the average age of individuals with severe autism in Ray's study was 8.17 years, whereas the average age of children with RA in our study was 3.13 years. A potential explanation for the discrepancy is that the expression of APP and its metabolites differs during the various stages of childhood. It is not clear whether the activity of the toxic metabolic pathway that produces sAPP $\beta$ gradually declines with age, the level of sAPP $\alpha$ increases with age, and its physiological effect is beneficial. This hypothesis needs to be verified by prospective cohort studies with longer-term observations in the future.

\section{LIMITATIONS}

There are limitations to our study. For example, children were included based on retrospective reports of parents, which may have affected our results. Therefore, a prospective study of children with RA might more accurately reveal the dynamic changes in the levels of APP and metabolites in these individuals.

\section{CONCLUSIONS}

Clarifying the common neurobiological mechanisms of neurodevelopmental disorders and neurodegenerative disease may be useful in identifying early disease biomarkers. Importantly, we observed that plasma levels of sAPP $\alpha$ and sAPPtotal were elevated in early childhood in individuals with RA. Increased plasma levels of sAPPtotal and $\operatorname{sAPP} \alpha$ may be secondary changes in response to another pathological change

\section{REFERENCES}

1. Lord C, Elsabbagh M, Baird G, Veenstra-Vanderweele J. Autism spectrum disorder. Lancet. (2018) 392:508-20. doi: 10.1016/S0140-6736(18) 31129-2

2. Ssucharewa GE, Wolff S. The first account of the syndrome Asperger described? Translation of a paper entitled "Die schizoiden Psychopathien im Kindesalter” by Dr. G.E. Ssucharewa; scientific assistant, which appeared in 1926 in the Monatsschrift für Psychiatrie und Neurologie 60:235-261. Eur Child Adolesc Psychiatry. (1996) 5:119-32.

3. Maenner MJ, Shaw KA, Baio J, EdS1, Washington A, Patrick M, et al. Prevalence of autism spectrum disorder among children aged 8 years - autism and developmental disabilities monitoring network, 11 Sites, United States, 2016. Morbid Mortal Wkly Rep Surveill Summar. (2020) 69:112. doi: $10.15585 / \mathrm{mmwr} . s s 6904 \mathrm{a} 1$ that might be the causal pathology. Our study may be valuable biomarkers for the early identification of ASD regression.

Prospective studies will be conducted using a larger sample to further investigate these differences.

\section{DATA AVAILABILITY STATEMENT}

The raw data supporting the conclusions of this article will be made available by the authors, without undue reservation.

\section{ETHICS STATEMENT}

The studies involving human participants were reviewed and approved by the Ethics Committee of the Children's Hospital of Chongqing Medical University (approval number (2019) IRB (Study) No. 292). Written informed consent to participate in this study was provided by the participants' legal guardian/next of kin.

\section{AUTHOR CONTRIBUTIONS}

TL and LC conceived and designed the experiments. XLi, PZ, and QL performed the experiments. BP, YC, YD, HW, XLiu, YY, QF, YZ, ZJ, TY, JC, and QC contributed reagents, materials, analysis tools. XLi and LC wrote the paper. All authors contributed to the article and approved the submitted version.

\section{FUNDING}

This study was supported by the Youth Innovation Team of Future Medical Support Plan of Chongqing Medical University (W0037), the Guangzhou Key Project Early diagnosis and treatment of autism spectrum disorders (202007030002), and the Guangdong Key Project Development of new tools for diagnosis and treatment of autism (2018B030335001).

\section{ACKNOWLEDGMENTS}

We want to thank all the staff of the Rongzhi and Jiekang specialized educational institutions for their support for the study and the parents of the subjects who participated in this study.

4. Courchesne E, Pramparo T, Gazestani VH, Lombardo MV, Pierce K, Lewis NE. The ASD living biology: from cell proliferation to clinical phenotype. $\mathrm{Mol}$ Psychiatry. (2019) 24:88-107. doi: 10.1038/s41380-018-0056-y

5. Matelski L, Van de Water J. Risk factors in autism: thinking outside the brain. J Autoimmunity. (2016) 67:1-7. doi: 10.1016/j.jaut.2015.11.003

6. Zwaigenbaum L, Penner M. Autism spectrum disorder: advances in diagnosis and evaluation. Bmj. (2018) 361:k1674. doi: 10.1136/bmj.k1674

7. van 't Hof M, Tisseur C, van Berckelear-Onnes I, van Nieuwenhuyzen A, Daniels AM, Deen M, et al. Age at autism spectrum disorder diagnosis: a systematic review and meta-analysis from 2012 to 2019. Autism. (2020) 25:862-73. doi: 10.1177/1362361320971107

8. Ozonoff S, Iosif AM. Changing conceptualizations of regression: what prospective studies reveal about the onset of autism spectrum disorder. Neurosci Biobehav Rev. (2019) 100:296304. doi: 10.1016/j.neubiorev.2019.03.012 
9. Hyman SL, Levy SE, Myers SM. Identification, evaluation, and management of children with autism spectrum disorder. Pediatrics. (2020) 145:e20193447. doi: 10.1542/9781610024716-part01-ch002

10. Vitiello B. Editorial: targeting the core symptoms of autism spectrum disorder with mechanism-based medications. J Am Acad Child Adolesc Psychiatry. (2021) 60:816-7. doi: 10.1016/j.jaac.2020.11.006

11. Tonge BJ, Bull K, Brereton A, Wilson R. A review of evidence-based early intervention for behavioural problems in children with autism spectrum disorder: the core components of effective programs, child-focused interventions and comprehensive treatment models. Curr Opin Psychiatry. (2014) 27:158-65. doi: 10.1097/YCO.0000000000000043

12. Zhang D, Bedogni F, Boterberg S, Camfield C, Camfield P, Charman T, et al. Towards a consensus on developmental regression. Neurosci Biobehav Rev. (2019) 107:3-5. doi: 10.1016/j.neubiorev.2019.08.014

13. Boterberg S, Van Coster R, Roeyers H. Characteristics, early development and outcome of parent-reported regression in autism spectrum disorder. J Autism Dev Disord. (2019) 49:4603-25. doi: 10.1007/s10803-019-04183-x

14. Thompson L, Gillberg C, Landberg S, Kantzer AK, Miniscalco C, Barnevik Olsson M. Autism with and without regression: a two-year prospective longitudinal study in two population-derived Swedish cohorts. J Autism Dev Disord. (2019) 49:2281-90. doi: 10.1007/s10803-018-03871-4

15. Boterberg S, Charman T, Marschik PB, Bölte S, Roeyers H. Regression in autism spectrum disorder: a critical overview of retrospective findings and recommendations for future research. Neurosci Biobehav Rev. (2019) 102:2455. doi: 10.1016/j.neubiorev.2019.03.013

16. Tan C, Frewer V, Cox G, Williams K, Ure A. Prevalence and age of onset of regression in children with autism spectrum disorder: a systematic review and meta-analytical update. Autism Res. (2021) 14:582-98. doi: 10.1002/aur.2463

17. Dale RC. Autistic regression and central nervous system autoimmunity. Dev Med Child Neurol. (2016) 58:1002-3. doi: 10.1111/dmcn.13185

18. Scott O, Shi D, Andriashek D, Clark B, Goez HR. Clinical clues for autoimmunity and neuroinflammation in patients with autistic regression. Dev Med Child Neurol. (2017) 59:947-51. doi: 10.1111/dmcn.13432

19. Rangel-Huerta O, Gomez-Fernández A, de la Torre-Aguilar M, Gil A, Perez-Navero J, Flores-Rojas K, et al. Metabolic profiling in children with autism spectrum disorder with and without mental regression: preliminary results from a cross-sectional case-control study. Metabolomics. (2019) 15:99. doi: 10.1007/s11306-019-1562-x

20. Ashwood P, Krakowiak P, Hertz-Picciotto I, Hansen R, Pessah I, Van de Water J. Elevated plasma cytokines in autism spectrum disorders provide evidence of immune dysfunction and are associated with impaired behavioral outcome. Brain Behav Immun. (2011) 25:40-5. doi: 10.1016/j.bbi.2010.08.003

21. Carter C. Autism genes and the leukocyte transcriptome in autistic toddlers relate to pathogen interactomes, infection and the immune system. A role for excess neurotrophic sAPP $\alpha$ and reduced antimicrobial A $\beta$. Neurochem Int. (2019) 126:36-58. doi: 10.1016/j.neuint.2019.03.007

22. Priller C, Bauer T, Mitteregger G, Krebs B, Kretzschmar HA, Herms J. Synapse formation and function is modulated by the amyloid precursor protein. $J$ Neurosci. (2006) 26:7212-21. doi: 10.1523/JNEUROSCI.1450-06.2006

23. Hefter D, Ludewig S, Draguhn A, Korte M. Amyloid, APP, and electrical activity of the brain. Neuroscientist. (2020) 26:23151. doi: 10.1177/1073858419882619

24. Haass C, Selkoe DJ. Cellular processing of beta-amyloid precursor protein and the genesis of amyloid beta-peptide. Cell. (1993) 75:103942. doi: 10.1016/0092-8674(93)90312-E

25. Mullan M, Crawford F. Genetic and molecular advances in Alzheimer's disease. Trends Neurosci. (1993) 16:398403. doi: 10.1016/0166-2236(93)90007-9

26. Nguyen KV. The human $\beta$-amyloid precursor protein: biomolecular and epigenetic aspects. Biomol Concepts. (2015) 6:11-32. doi: 10.1515/bmc-2014-0041

27. Hampel H, Vassar R, De Strooper B, Hardy J, Willem M, Singh N. The $\beta$-secretase BACE1 in Alzheimer's disease. Biol Psychiatry. (2020) 89:74556. doi: 10.1016/j.biopsych.2020.02.001

28. Turner PR, O'Connor K, Tate WP, Abraham WC. Roles of amyloid precursor protein and its fragments in regulating neural activity, plasticity and memory. Progr Neurobiol. (2003) 70:1-32. doi: 10.1016/S0301-0082(03)00089-3
29. Sokol DK, Chen D, Farlow MR, Dunn DW, Maloney B, Zimmer JA, et al. High levels of Alzheimer beta-amyloid precursor protein (APP) in children with severely autistic behavior and aggression. J Child Neurol. (2006) 21:4449. doi: 10.1177/08830738060210062201

30. Bailey AR, Hou H, Song M, Obregon DF, Portis S, Barger S, et al. GFAP expression and social deficits in transgenic mice overexpressing human sAPP $\alpha$. Glia. (2013) 61:1556-69. doi: 10.1002/glia.22544

31. Kern JK, Geier DA, Sykes LK, Geier MR. Evidence of neurodegeneration in autism spectrum disorder. Transl Neurodegener. (2013) 2:17. doi: 10.1186/2047-9158-2-17

32. Li Q, Yang T, Chen L, Dai Y, Wu LJ, Jia FY. Serum folate status is primarily associated with neurodevelopment in children with autism spectrum disorders aged three and under-a multi-center study in China. Front Nutr. (2021) 8:661223. doi: 10.3389/fnut.2021.661223

33. Zwaigenbaum L. Perspectives on regressive onset in autism: looking forward on looking back. Neurosci Biobehav Rev. (2019) 103:399-400. doi: 10.1016/j.neubiorev.2019.06.025

34. Jones LA, Campbell JM. Clinical characteristics associated with language regression for children with autism spectrum disorders. J Autism Dev Disord. (2010) 40:54-62. doi: 10.1007/s10803-009-0823-3

35. Malhotra S, Gupta N. Childhood disintegrative disorder. J Autism Dev Disord. (1999) 29:491-8. doi: 10.1023/A:1022247903401

36. Hendry CN. Childhood disintegrative disorder: should it be considered a distinct diagnosis? Clin Psychol Rev. (2000) 20:77-90. doi: 10.1016/S0272-7358(98)00094-4

37. Erickson CA, Ray B, Maloney B, Wink LK, Bowers K, Schaefer TL. Impact of acamprosate on plasma amyloid- $\beta$ precursor protein in youth: a pilot analysis in fragile $\mathrm{X}$ syndrome-associated and idiopathic autism spectrum disorder suggests a pharmacodynamic protein marker. J Psychiatr Res. (2014) 59:220-8. doi: 10.1016/j.jpsychires.2014.07.011

38. Perneczky R, Guo LH, Kagerbauer SM, Werle L, Kurz A, Martin J, et al. Soluble amyloid precursor protein $\beta$ as blood-based biomarker of Alzheimer's disease. Transl Psychiatry. (2013) 3:e227. doi: 10.1038/tp.2013.11

39. Alexopoulos P, Gleixner LS, Werle L, Buhl F, Thierjung N, Giourou E, et al. Plasma levels of soluble amyloid precursor protein $\beta$ in symptomatic Alzheimer's disease. Eur Arch Psychiatry Clin Neurosci. (2018) 268:51924. doi: 10.1007/s00406-017-0815-9

40. Heller T. Über Dementia infantilis: Verblödungsprozeß im Kindesalter. Zeitschrift Erforschung Behandlung Jugendlichen Schwachsinns. (1908) 2:1728.

41. Shooshtari S, Martens PJ, Burchill CA, Dik N, Naghipur S. Prevalence of depression and dementia among adults with developmental disabilities in Manitoba, Canada. Int J Family Med. (2011) 2011:319574. doi: 10.1155/2011/319574

42. Frackowiak J, Mazur-Kolecka B, Mehta P, Wegiel J. Enhanced accumulation of N-terminally truncated $A \beta$ with and without pyroglutamate11 modification in parvalbumin-expressing GABAergic neurons in idiopathic and dup15q11.2-q13 autism. Acta Neuropathol Commun. (2020) 8:58. doi: 10.1186/s40478-020-00923-8

43. Corbett NJ, Hooper NM. Soluble amyloid precursor protein $\alpha$ : friend or foe? Adv Exp Med Biol. (2018) 1112:177-83. doi: 10.1007/978-981-13-3065-0_13

44. Gakhar-Koppole N, Hundeshagen P, Mandl C, Weyer SW, Allinquant B, Müller U. Activity requires soluble amyloid precursor protein alpha to promote neurite outgrowth in neural stem cell-derived neurons via activation of the MAPK pathway. Eur J Neurosci. (2008) 28:87182. doi: 10.1111/j.1460-9568.2008.06398.x

45. Roch JM, Masliah E, Roch-Levecq AC, Sundsmo MP, Otero DA, Veinbergs I, et al. Increase of synaptic density and memory retention by a peptide representing the trophic domain of the amyloid beta/A4 protein precursor. Proc Natl Acad Sci USA. (1994) 91:7450-4. doi: 10.1073/pnas.91.16.7450

46. Caillé I, Allinquant B, Dupont E, Bouillot C, Langer A, Müller U, et al. Soluble form of amyloid precursor protein regulates proliferation of progenitors in the adult subventricular zone. Development. (2004) 131:217381. doi: 10.1242/dev.01103

47. Kwak YD, Brannen CL, Qu T, Kim HM, Dong X, Soba P, et al. Amyloid precursor protein regulates differentiation of human neural stem cells. Stem Cells Dev. (2006) 15:381-9. doi: 10.1089/scd.2006.15.381 
48. Taylor CJ, Ireland DR, Ballagh I, Bourne K, Marechal NM, Turner PR, et al. Endogenous secreted amyloid precursor protein-alpha regulates hippocampal NMDA receptor function, long-term potentiation and spatial memory. Neurobiol Dis. (2008) 31:250-60. doi: 10.1016/j.nbd.2008. 04.011

49. Goodman Y, Mattson MP. Secreted forms of beta-amyloid precursor protein protect hippocampal neurons against amyloid beta-peptide-induced oxidative injury. Exp Neurol. (1994) 128:1-12. doi: 10.1006/exnr.1994.1107

50. Fol R, Braudeau J, Ludewig S, Abel T, Weyer SW, Roederer JP, et al. Viral gene transfer of APPs $\alpha$ rescues synaptic failure in an Alzheimer's disease mouse model. Acta Neuropathol. (2016) 131:247-66. doi: 10.1007/s00401-015-1498-9

51. Rieche F, Carmine-Simmen K, Poeck B, Kretzschmar D, Strauss R. Drosophila full-length amyloid precursor protein is required for visual working memory and prevents age-related memory impairment. Curr Biol. (2018) 28:81723. doi: 10.1016/j.cub.2018.01.077

52. Obregon D, Hou H, Deng J, Giunta B, Tian J, Darlington D, et al. Soluble amyloid precursor protein- $\alpha$ modulates $\beta$-secretase activity and amyloid- $\beta$ generation. Nat Commun. (2012) 103:777. doi: 10.1038/ncomms1781

53. Tang G, Gudsnuk K, Kuo SH, Cotrina ML, Rosoklija G, Sosunov A. Loss of mTOR-dependent macroautophagy causes autistic-like synaptic pruning deficits. Neuron. (2014) 83:1131-43. doi: 10.1016/j.neuron.2014. 09.001

54. Vogel-Ciernia A, Wood MA. Neuron-specific chromatin remodeling: a missing link in epigenetic mechanisms underlying synaptic plasticity, memory, and intellectual disability disorders. Neuropharmacology. (2014) 80:18-27. doi: 10.1016/j.neuropharm.2013.10.002

55. Ebert DH, Greenberg ME. Activity-dependent neuronal signalling and autism spectrum disorder. Nature. (2013) 493:327-37. doi: 10.1038/nature 11860

56. Griffin W, Liu L, Li Y, Mrak R, Barger S. Interleukin-1 mediates Alzheimer and Lewy body pathologies. J Neuroinflamm. (2006) 3:5. doi: 10.1186/1742-2094-3-5

57. Kwak YD, Dantuma E, Merchant S, Bushnev S, Sugaya K. Amyloid- $\beta$ precursor protein induces glial differentiation of neural progenitor cells by activation of the IL-6/gp130 signaling pathway. Neurotox Res. (2010) 18:32838. doi: 10.1007/s12640-010-9170-6

58. Mangiola F, Ianiro G, Franceschi F, Fagiuoli S, Gasbarrini G, Gasbarrini A. Gut microbiota in autism and mood disorders. World J Gastroenterol. (2016) 22:361-8. doi: 10.3748/wjg.v22.i1.361

59. Fattorusso A, Di Genova L, Dell'Isola GB, Mencaroni E, Esposito S. Autism spectrum disorders and the gut microbiota. Nutrients. (2019) 11:521. doi: 10.3390/nu11030521

60. Israelyan N, Margolis KG. Serotonin as a link between the gut-brainmicrobiome axis in autism spectrum disorders. Pharmacol Res. (2018) 132:16. doi: 10.1016/j.phrs.2018.03.020
61. Yap CX, Henders AK, Alvares GA, Wood DLA, Krause L, Tyson $\mathrm{GW}$, et al. Autism-related dietary preferences mediate autism-gut microbiome associations. Cell. (2021) 184:5916-31. doi: 10.1016/j.cell.2021. 10.015

62. Campion D, Ponzo P, Alessandria C, Saracco GM, Balzola F. The role of microbiota in autism spectrum disorders. Minerva Gastroenterol Dietol. (2018) 64:333-50. doi: 10.23736/S1121-421X.18.02493-5

63. Ma Q, Xing C, Long W, Wang HY, Liu Q, Wang RF. Impact of microbiota on central nervous system and neurological diseases: the gut-brain axis. $J$ Neuroinflamm. (2019) 16:53. doi: 10.1186/s12974-019-1434-3

64. Kumar DK, Choi SH, Washicosky KJ, Eimer WA, Tucker S, Ghofrani $J$, et al. Amyloid- $\beta$ peptide protects against microbial infection in mouse and worm models of Alzheimer's disease. Sci Transl Med. (2016) 8:340ra72. doi: 10.1126/scitranslmed.aaf1059

65. Kesika P, Suganthy N, Sivamaruthi BS, Chaiyasut C. Role of gut-brain axis, gut microbial composition, and probiotic intervention in Alzheimer's disease. Life Sci. (2021) 264:118627. doi: 10.1016/j.lfs.2020.118627

66. Takata F, Nakagawa S, Matsumoto J, Dohgu S. Blood-brain barrier dysfunction amplifies the development of neuroinflammation: understanding of cellular events in brain microvascular endothelial cells for prevention and treatment of bbb dysfunction. Front Cell Neurosci. (2021) 15:661838. doi: $10.3389 /$ fncel.2021.661838

67. Ray B, Long JM, Sokol DK, Lahiri DK. Increased secreted amyloid precursor protein- $\alpha(\operatorname{sAPP} \alpha)$ in severe autism: proposal of a specific, anabolic pathway and putative biomarker. PLOS ONE. (2011) 6:e20405. doi: 10.1371/journal.pone.0020405

Conflict of Interest: The authors declare that the research was conducted in the absence of any commercial or financial relationships that could be construed as a potential conflict of interest.

Publisher's Note: All claims expressed in this article are solely those of the authors and do not necessarily represent those of their affiliated organizations, or those of the publisher, the editors and the reviewers. Any product that may be evaluated in this article, or claim that may be made by its manufacturer, is not guaranteed or endorsed by the publisher.

Copyright (c) 2022 Li, Zhou, Li, Peng, Cun, Dai, Wei, Liu, Yu, Jiang, Fan, Zhang, Yang, Chen, Cheng, Li and Chen. This is an open-access article distributed under the terms of the Creative Commons Attribution License (CC BY). The use, distribution or reproduction in other forums is permitted, provided the original author(s) and the copyright owner(s) are credited and that the original publication in this journal is cited, in accordance with accepted academic practice. No use, distribution or reproduction is permitted which does not comply with these terms. 